\title{
INCLUSÃO NA EDUCAÇÃO DE JOVENS E ADULTOS
}

\author{
JANe Paiva ${ }^{1}$ \\ Faculdade de Educação, Universidade Estadual do Rio de Janeiro \\ E-mail: janepaiva@terra.com.br
}

\section{RESUMO}

$\mathrm{O}$ artigo apresenta alguns elementos de reflexão quanto ao significado de inclusão na educação de jovens e adultos (EJA), partindo de premissas que sustentam ofertas de escolarização, tendo foco no conhecimento sobre quem são esses jovens e adultos que se quer incluir. Sustenta posição de desconfiança no conceito de inclusão que, de forma irrestrita, vem sendo utilizado para tratar direito, concordando com Martins (2009, p. 11) no que denomina de "transformação do conceito na palavra sem sentido" ao se referir à exclusão. Ensaiamse algumas implicações pedagógicas e políticas resultantes das formas de conceber umas e outras, e como essas formas afetam os desenhos propostos como política pública, em programas de EJA - e de educação profissional. Apontam-se alguns indicativos metodológicos considerados fundamentos para este campo de estudos e proposições, constituídos pelos muitos modos de pensar/fazer PROEJA nos Institutos Federais brasileiros, calcados na perspectiva de formulação de políticas educacionais como direito, nos termos da Constituição Federal (1988). Sustenta que trançar políticas de direito com sujeitos jovens e adultos tem sido o desafio maior de gestores e de forças organizadas da sociedade, o que significa levar em conta saberes cotidianos, prévios, muitas vezes ignorados pelos espaços escolares institucionalizados, encobrindo experiências sociais, históricas, culturais, de classe, de sociedade, de professores e de alunos - os saberes e conhecimentos produzidos na vida cotidiana, que formam redes passíveis de emergir na realidade da escola como emergem na realidade da vida. Conceber essa proposta de educação para jovens e adultos trabalhadores significa inseri-la na conformação de um campo de produção de conhecimentos reconhecido por Boaventura de Sousa Santos (2010) como de epistemologias do Sul.

Palavras-chave: PROEJA, educação profissional, inclusão, educação de jovens e adultos.

A democracia é subversiva. E é subversiva no sentido mais radical da palavra, porque, ali onde ela chega, subverte a concepção tradicional do poder, tão tradicional que é considerada natural, segundo a qual o poder - seja o poder político ou o econômico, seja o poder paterno ou o sacerdotal - vem de cima para baixo. (BOBBIO apud WEFFORT, 1992, p. 119).

\section{INTRODUÇÃO}

Para apresentar alguns elementos de reflexão quanto ao significado de inclusão na educação de jovens e adultos (EJA) que contribuam para o debate, inicio pelas indispensáveis premissas de sustentação de ofertas de escolarização de sujeitos jovens e adultos, tendo foco no conhecimento sobre quem são esses jovens e adultos que se quer incluir.

De posse desses elementos, ensaiarei algumas implicações pedagógicas e políticas resultantes dessas formas de conceber umas e outras que afetam os desenhos que vêm sendo propostos como política pública, em programas de EJA - e de educação profissional - , ousando apontar, por fim, alguns indicativos metodológicos que considero fundamentos para este campo de estudos e proposições que se constituem estimulados pelos muitos modos de pensar/fazer PROEJA em tantos Institutos Federais pelo Brasil afora.

Parto, pois, da inevitabilidade de formular políticas educacionais como direito, nos termos da Constituição Federal (1988), em se tratando de jovens e adultos (trabalhadores), o que exige tomar essa condição como preceito sobre o qual tudo o mais se assenta, rompendo:

[...] com a dualidade estrutural cultura geral versus cultura técnica, situação que viabiliza a oferta de uma educação academicista para os filhos das classes favorecidas sócioeconomicamente e uma educação instrumental voltada para o trabalho para os filhos da

\footnotetext{
${ }^{1}$ Jane Paiva é professora adjunta da UERJ, atuando na Faculdade de Educação e no Programa de Pós-Graduação em Educação (PROPED), na linha de pesquisa Educação inclusiva e processos educacionais, que integra com estudos e pesquisas no campo da educação de jovens e adultos.
} 
classe trabalhadora, o que se tem chamado de uma educação pobre para os pobres. (BRASIL, 2006).

Trata-se, portanto, de (re)pensar que direito à educação, por princípio, significa formação humana, que se fundamenta:

[...] na integração de trabalho, ciência, técnica, tecnologia, humanismo e cultura geral, [...] contribuir para o enriquecimento científico, cultural, político e profissional das populações, pela indissociabilidade dessas dimensões no mundo real. Ademais, essas dimensões estão estreitamente vinculadas às condições necessárias ao efetivo exercício da cidadania. (BRASIL, 2006).

E ainda:

[...] A formação assim pensada contribui para a integração social do educando, o que compreende o mundo do trabalho, sem resumir-se a ele, assim como compreende a continuidade de estudos. Em síntese, a oferta organizada se faz orientada a proporcionar a formação de cidadãos-profissionais capazes de compreender a realidade social, econômica, política, cultural e do mundo do trabalho, para nela inserir-se e atuar de forma ética e competente, técnica e politicamente, visando à transformação da sociedade em função dos interesses sociais e coletivos - especialmente os da classe trabalhadora. (BRASIL, 2006).

Trançar políticas de direito com os sujeitos a quem são devidas essas políticas tem sido o desafio maior de gestores e de forças organizadas da sociedade, o que significa levar em conta saberes cotidianos, prévios, quase sempre ignorados pelos espaços escolares institucionalizados, que encobrem experiências sociais, históricas, culturais, de classe, de sociedade, de professores e de alunos, evitando trançar histórias e trançar com elas saberes, conhecimentos, produzidos nessa vida cotidiana, formando redes que passam a emergir na realidade da escola como emergem na realidade da vida. Assumo aqui que conceber essa proposta de educação para jovens e adultos se insere na conformação de um campo de produção de conhecimentos que poderia ser reconhecido por Boaventura de Sousa Santos (2010) como de epistemologias do Sul.

Por fim, gostaria de sustentar minha posição de desconfiança no conceito que, de forma irrestrita, vem sendo utilizado para tratar direito: inclusão.

Apesar de muitos de nós nos inserirmos em linhas de pesquisa e campos assim denominados, gostaria de concordar com Martins (2009, p. 11) no que denomina de "transformação do conceito na palavra sem sentido" ao se referir à exclusão. Por oposição, tomo a argumentação do autor, assumindo também entender que inclusão tornou-se essa palavra sem sentido que, ao ser alavancada, "desdiz o que aparentemente quer dizer. [...] Ao invés de a palavra expressar uma prática, rica, aliás, ela acaba induzindo a uma prática, pobre aliás", encobrindo-se, de fato, a nova desigualdade gerada pelo que tem sido chamado de exclusão. Na sequência, Martins (2009, p. 14) ainda vai afirmar:

[...] não existe exclusão: existe contradição, existem vítimas de processos sociais, políticos e econômicos excludentes; existe o conflito pelo qual a vítima dos processos excludentes proclama seu inconformismo, seu mal-estar, sua revolta, sua esperança, sua força reivindicativa e sua reivindicação corrosiva. Essas reações, porque não se trata estritamente de exclusão, não se dão fora dos sistemas econômicos e dos sistemas de poder. Elas constituem o imponderável de tais sistemas, fazem parte deles ainda que os negando. As reações não ocorrem de fora para dentro; elas ocorrem no interior da realidade problemática, 'dentro' da realidade que produziu os problemas que as causam.

Para o autor, a exclusão substitui a ideia de processos de exclusão, e em vez de ser concebida como expressão da contradição no desenvolvimento da sociedade capitalista, passa a ser vista como um estado, uma coisa fixa, irremediável e fatal (MARTINS, 2009, p. 16-17).

Chama-se atenção, entretanto, que a forma de considerar excluídos os até então marginalizados (de direitos sociais) tem referência à exclusão do consumo, ou seja, aos bens econômicos, e quando o acesso a esses bens se dá gera a ilusão de inclusão, apartada da consciência de que são os direitos sociais os fatores integradores e produtores da condição cidadã.

A sociedade exclui para incluir e esta transmutação é condição da ordem social desigual, o que implica o caráter ilusório da inclusão. Todos estamos inseridos de algum modo, nem sempre decente e digno, no 
circuito reprodutivo das atividades econômicas, sendo a grande maioria da humanidade inserida através da insuficiência e das privações, que se desdobram para fora do econômico. (SAWAIA, 2009, p.8).

Apesar de todas essas observações - e até mesmo objeções - e admitindo que a questão da educação de jovens e adultos inclui a perspectiva de inclusão em sociedades democráticas, bem como que esta inclusão passa a se dar pela conquista de direitos, ressalto que matrizes conceituais como direito e democracia são, portanto, conceitos fundantes da ampliação da compreensão do que é a EJA na contemporaneidade.

\section{Premissas Iniciais Para PENSAR o Conceito de Direito À EduCAÇão}

A questão do direito na vida das populações e das sociedades, tal como se o entende nos dias atuais, passa por largos processos de construção de práticas e de sentidos, historicamente constituidores da noção teórica que diversos autores vêm estudando e formulando, para entendimento das relações de poder nas sociedades.

Bobbio (1992, p. 5) aponta que:

[...] os direitos do homem, por mais fundamentais que sejam, são direitos históricos, ou seja, nascidos em certas circunstâncias, caracterizadas por lutas em defesa de novas liberdades contra velhos poderes, e nascidos de modo gradual, não todos de uma vez e nem de uma vez por todas.

Direito $a$, portanto, emerge em um conjunto de oposições existentes em práticas sociais a que alguns têm acesso e outros não, tanto configurando a negação de participar dessas práticas, quanto o privilégio de alguns de poder participar dessas mesmas práticas: alfabetizado - não-alfabetizado; escolarizado - nãoescolarizado; leitor - não-leitor; incluído - excluído; e, ainda, os conceitos de analfabetos - analfabetos funcionais; desescolarizados; e não-incluídos, todos eles refletindo a situação de sujeitos segundo as condições de acesso a alguns direitos - sociais, nesses casos - caros ao exercício da cidadania.

Essas oposições, visíveis para mim no campo educacional a partir do interesse que me despertam, porque aproximam ou afastam e até mesmo apartam sujeitos de fundamentos/instrumentos das sociedades grafocêntricas - o saber ler e escrever - , desempenham, nessa mesma sociedade, de classe, capitalista, um papel decisório para definir o lugar social dos sujeitos que por ela são categorizados. Categorias essas que se hierarquizam no mesmo modelo social, quando se parte do que se pode considerar o "grau" menor - talvez o não-alfabetizado - , seguindo-se até a um topo, que tanto se identifica com o status de leitor, quanto com o de escolarizado.

Para alguns, a condição de passar de um lado a outro dessas oposições (saindo do que representa o nulo para o pleno) constituiu um privilégio, enquanto para outros, trata-se de dom, de direito natural, inconteste.

Como todas elas dizem respeito a uma construção social conhecida como direito à educação - forma pela qual o conhecimento é alcançado, por meio de um sistema codificado, tornado bem cultural simbólico das civilizações - ter acesso, ou não, a esse bem constitui o direito e, por oposição, não ter acesso, o não-direito, frequentemente traduzido como exclusão/apartação, por não ser ele direito natural, mas construção social.

Ao longo da história da educação podem-se acompanhar diversos modos como o direito à educação veio sendo conquistado, destacando-se algumas personagens como centrais nessa história. No Brasil, uma delas, Anísio Teixeira, para quem "a educação é um direito" (NUNES, 1996, p. 7), título e tema de seu terceiro livro publicado em 1968, que se segue a um segundo, de 1957, cuja tese é "educação não é privilégio", ambas consideradas fundamentos das formas democráticas de vida social. Seu pensamento sobre educação e formas de mudança para a situação da escola brasileira, além de sua capacidade de intervir na realidade, exercendo funções de destaque, aliaram teoria e prática política. Outro personagem é Paulo Freire, para quem a concepção libertadora da educação é, sem dúvida, a síntese pela qual reúne o método democrático e a forma do direito para tratar de um conteúdo - a liberdade - que resume o caráter humanizador da educação.

Paulo Freire, cujos vínculos com a cultura antropológica determinou outro olhar sobre os processos educativos, fez na prática, mais do que no discurso, a vivência da democracia. Buscando compreender os fenômenos de nossa formação social, pelo ponto de vista psicossocial e como a questão da opressão se introduz e se instala no universo subjetivo do próprio oprimido, produzindo não apenas atitudes submissas, mas extremamente autoritárias quando em situação favorecida - oprimidos que oprimem, aderentes ao conteúdo do opressor - Freire revela intensa preocupação com a desigualdade das relações de poder da sociedade e as necessárias rupturas para que outras práticas mais igualitárias possibilitem a conquista de direitos iguais para todos.

Ao mesmo tempo, Freire experimenta e busca práticas educativas que incorporam a sociedade nas escolhas político-pedagógicas, fazendo-a participar da proposição de novos projetos que interessem a classes 
sociais diferenciadas, com o objetivo da equidade, e defende o papel do sistema público como espaço de direito de todos a ser modificado, alterado, pela participação de novos sujeitos no cenário escolar.

Para além do sentido do educar que cabe à escola, Freire incorporou, no breve tempo passado à frente da Secretaria Municipal de Educação de São Paulo, durante o mandato de Luísa Erundina (1989-1992), amplos setores da sociedade nas múltiplas tarefas que assumiu para consubstanciar uma educação para todos, porque até então muitos eram excluídos do debate, por não se considerar a função educadora que toda a sociedade e suas instâncias estruturais e conjunturais - produz nos sujeitos.

Não hesitaria em afirmar que, tendo-se tornado historicamente o ser mais a vocação ontológica de mulheres e homens, será a democrática a forma de luta ou de busca mais adequada à realização humana do ser mais. Há, assim, um fundamento ontológico e histórico para a luta política em torno não apenas da democracia mas de seu constante aperfeiçoamento. (FREIRE, 1994, p. 185).

Paulo Freire, nesta afirmação, impõe-se a mim para pensar o sentido educador - e até mesmo pedagógico - que a condição humana, em busca do ser mais, fundamenta na luta política pela igualdade e pela liberdade, o que passa a ser possível, no plano histórico, por meio da vivência do método democrático.

Esta questão remete-me a duas considerações: a primeira, a que considera suficiente defender o acesso à escola para todos como modo de assegurar a base democrática; e a segunda, a que exige interrogar o modelo de democracia do qual se fala. A primeira consideração interage imediatamente com o campo de estudos em que transito, o da educação de jovens e adultos, especificamente quando se a defende como direito. Para o Estado democrático, é dever estrito proporcionar educação a todas as crianças, jovens e adultos. Portanto, "o Estado neocapitalista, já que dificilmente chega a ser democrático, não pode ser menos que liberal". (BOSI, 1992, p. 341).

Para a segunda, interrogando o modelo de democracia do qual se fala, apóio-me ainda em Bosi (1992, p. 341):

Se o projeto educacional brasileiro fosse realmente democrático, se ele quisesse penetrar, de fato, na riqueza da sociedade civil, ele promoveria a um plano prioritário tudo quanto significasse, na cultura erudita (universitária ou não), um dobrar-se atento à vida e à expressão do povo; e, igualmente, tudo quanto fosse uma reflexão sobre as possibilidades, ou as imposturas, veiculadas pela indústria e pelo comércio cultural. Friso as duas direções: uma, de acolhimento e entendimento profundo das manifestações e aspirações populares; outra, de controle e de crítica, ou, positivamente, de orientação das mensagens veiculadas pelos meios que atingem a massa da população.

Para Freire, é esse exatamente o sentido de um projeto educador: não apenas ensinar a letra, mas levar o homem à consciência de si, do outro, da natureza.

Sintetizando essa questão, o educador propõe-se, na Décima Quarta Carta do livro Cartas a Cristina (FREIRE, 1994, p. 183-184), a tomá-la, como objeto da curiosidade intelectual, formulando-a do seguinte modo: "que queremos dizer quando dizemos educação e democracia?". E, logo em seguida, indaga: "é possível ensinar democracia? Que significa educar para a democracia?"

Para compreender a questão proposta, remete suas reflexões às relações contraditórias, dialéticas entre autoridade e liberdade, assinalando que, no entanto, essas reflexões não podem se fazer afastadas das questões que envolvem o poder, o econômico, a igualdade, a justiça, a ética. Reconhece, assim, que a democracia não prescinde de fundamentos ontológicos e históricos - a vocação humana do ser mais -, o que implica não restringi-la, apenas, à dimensão política ${ }^{2}$, com o que se negaria a si mesma.

Uma ideia central em seu pensamento é a de que a luta incessante em favor da democratização da sociedade implica a democratização da escola, e nesta a democratização dos conteúdos e do ensino. $\mathrm{E}$ alerta aos educadores progressistas que não há como esperar que a sociedade brasileira se democratize para que comecem a ter práticas democráticas na escola, lembrando que essas práticas não podem ser autoritárias hoje, para serem democráticas amanhã. (FREIRE, 1992, p. 113-114).

A discussão do sentido de direito, e de seus beneficiários, expõe outro lado da questão, ou seja, os não-incluídos nas diversas categorias do direito. Os processos de inclusão nos direitos sociais vão se fazendo como conquista; não são, em muitos casos, dados, o que significa dizer que não basta constituí-los como direitos para auferir de sua proteção. Nos processos de luta e conquista, pode-se falar de não-incluídos, admitindo-se que o serão gradativamente, no cumprimento do que passa a ser um dever para o Estado. No entanto, na prática, essa condição não permanece absoluta, sendo necessário admitir que a ela se juntarão os

\footnotetext{
${ }^{2}$ Freire assinala que, entendida assim, a democracia se limita ao direito do voto, que se oferece às massas populares, o que demonstra como historicamente esta sempre foi a escolha das elites, acentuando a desigualdade e a negação de direitos em geral, assim como as discriminações de toda a sorte, que negam a tolerância, para ele um sine qua da democracia.
} 
excluídos, ou seja, os que, já tendo sido incluídos algum dia, perderam a condição de sê-lo, por razão posta fora do sentido do direito, acirrando, de fato, as desigualdades.

A ideia, então, de exclusão/não-inclusão significa não permitir que cidadãos se beneficiem de direitos, por princípio, iguais para todos. Um ou outro sentido, no entanto, força o encontro de não-incluídos com os excluídos, dentre as múltiplas situações que revelam as desigualdades sociais e que, especificamente, o nãopertencimento ao benefício do direito à educação pode gerar, como alfabetizado/analfabeto/não-alfabetizado etc.

Buarque (2001, p.155), na obra singular de dicionarizar e reconstruir conceitos, cujos sentidos vêm sendo assumidos no mundo globalizado, assim escreve no verbete sobre exclusão:

As gerações anteriores não podiam imaginar a dimensão que seria alcançada pelas maravilhas criadas pelo avanço técnico, ao longo do século XX. Nem mesmo os escritores de ficção científica mais visionários conseguiram vislumbrar todos os benefícios que foram conquistados. Ainda menos poderiam conceber que imensa parte da humanidade estaria excluída de tais benefícios. Mesmo reconhecendo as dificuldades de uma delimitação clara da linha que separa excluídos e incluídos, sobretudo em face da dinâmica com que mudam gostos, desejos e possibilidades sociais, é possível assumir o conceito de exclusão no acesso aos bens e serviços essenciais.

Complementar a este, o autor, quando se refere ao conceito de incluídos, remete-se ao conceito de exclusão e, por oposição, conceitua o primeiro. Passo a citar parte de seu verbete, ampliando a conceituação, diversa da de Martins (2009):

Mas a história social não cumpriu a parte que lhe cabia no acordo, e uma parte considerável da humanidade ficou excluída dos benefícios. Ainda mais grave, o avanço técnico ocorreu a uma velocidade tão grande que passou a aumentar a desigualdade e ameaçar a estabilidade ecológica do planeta. A exclusão deixou de ser uma etapa a ser superada: é um estado no qual bilhões de seres humanos - os excluídos da modernidade - estão condenados. (BUARQUE, 2001, p. 188).

O que surpreende, nessa formulação, é o confronto com a ideia de que, por essa lógica, não há chance de superar a condição de não-incluído/excluído, porque para muitos direitos o caminho é sem volta, só restando o que o autor chama de condenação.

Esta condenação de que fala Buarque, parece ser ainda bastante visível no Brasil, apesar do processo de industrialização e urbanização pelo qual passou, desde a segunda metade dos anos 1990. Se por um lado a industrialização garantiu uma mudança radical nos modos de produção e definiu uma nova organização social e do mundo do trabalho, possibilitando ao país o ingresso em um concerto de nações de outro nível econômico, por outro fez-se à custa de processos de produção em que os homens trabalhadores e integrantes desses processos de desenvolvimento não viveram, nem como sujeitos, nem como trabalhadores, o próprio desenvolvimento, integrando os processos à margem deles, se isto é possível de ser pensado, sem acompanhar nem usufruir das aceleradas transformações a eles submetidas, para continuar a produzir lucro e competitividade. As mudanças não foram somente provocadas pela industrialização, mas também pela "reforma agrária" às avessas, que ocorreu quase no mesmo período. As exigências dessa "reforma agrária" incluíram projetos de educação tipicamente alternativos aos "modelos" urbanos, em disputa não apenas ao direito à educação, enunciado pelo Movimento dos Trabalhadores Rurais Sem Terra (MST), como também a um tipo de educação chamada "do campo", defensora e propagadora de valores da terra, de um ambiente sustentável e de um outro projeto de sociedade.

Não tem sido automática a assunção do direito à educação com o dever de oferta pelo Estado, e em inúmeros momentos a sociedade civil assume um protagonismo essencial na conquista de direitos. Semeraro, parafraseando Coutinho (1993) na análise das relações dos movimentos organizados com o Estado, em defesa de direitos, afirma:

É no decorrer das últimas décadas, de fato, que setores crescentes de trabalhadores perceberam as diversas formas da sociedade civil como um terreno importante de luta de classe, uma esfera privilegiada onde travar a intensa disputa pela hegemonia, um espaço político criativo e decisivo para avançar suas reivindicações, desenvolver as suas potencialidades subjetivas e sociais, para construir um consenso ativo entre forças convergentes e instituir formas de uma democracia popular capaz de recriar uma nova concepção de Estado e novas relações sócio-político-econômicas (SEMERARO, 1999, p. 7). 
Nessa perspectiva, como modalidade que é da educação básica, a EJA não pode ser pensada como oferta menor, nem menos importante. Modalidade é um modo próprio de fazer a educação básica, modo esse determinado pelos sujeitos que recebem: jovens e adultos.

O ensino fundamental (EF) ensaia, na modalidade EJA, inserção orgânica nas redes públicas nunca antes vista, por força de ações políticas induzidas pelo governo federal, que incluem o financiamento público. A oferta de ensino médio (EM), embora integrante da educação básica, mas não-constituído como direito ${ }^{3}$, é ainda restrita diante da demanda dos que se encontram em adequada relação idade-série, e na modalidade EJA apresenta pouca expressão, apesar dos esforços de programas nos últimos anos. Cabe lembrar, também, que nem o direito ao ensino fundamental, atribuído pela Constituição de 1988 a todos os brasileiros, foi ainda consagrado na prática, restando, portanto, um enorme desafio quando se pensam os sujeitos da EJA, pelos déficits históricos de atendimento desde a alfabetização.

\section{Quem é o Sujeito Jovem e Adulto? Ou Redescobrindo o Público da EJA para garantir o Direito À EDUCAÇÃo (A INCLUSÃo?)}

Paradoxalmente, jovens e adultos excluídos do direito à educação são os mesmos que integram a População Economicamente Ativa (PEA), produzindo, com sua força de trabalho, a riqueza do país. Tanto que, na análise de Furtado (Jornal do Brasil, 3 out 1993, p. 13), sobre a lógica da acumulação de riqueza, a condição da maioria dos brasileiros assim é exposta:

Durante 50 anos o Brasil cresceu mais do que qualquer país do mundo, alcançou uma das taxas de crescimento mais altas, $7 \%$ ao ano - a cada 10 anos o PIB dobrava. Mas o país fez isso acumulando miséria. $O$ crescimento é necessário, mas não suficiente.

O movimento de globalização do capitalismo, ao final do século XX, carregando consigo a globalização do mundo do trabalho, o que compreende tanto a questão social, quanto o movimento dos próprios trabalhadores, altera suas demandas educacionais. Tanto o mundo do trabalho quanto o dos trabalhadores apresentam características mundiais, ou seja, não se restringem apenas aos locais onde as relações se dão:

[...] são desiguais, estão dispersos pelo mundo, atravessando nações e nacionalidades, implicando diversidades e desigualdades sociais, econômicas, políticas, culturais, religiosas, lingüísticas, raciais e outras. Inclusive apresentam as particularidades de cada lugar, país ou região, por suas características históricas, geográficas e outras. Entretanto, há relações, processos e estruturas de alcance global que constituem o mundo do trabalho e estabelecem as condições do movimento operário. (IANNI, 1996, p. 17)

As modificações da organização da produção - o padrão flexível - também modificam as condições sociais e as técnicas de organização do trabalho, o que exige do trabalhador polivalência, abrindo perspectivas em sentidos diversos, ao mesmo tempo em que potencializa a força produtiva do trabalho, tornando-a mais técnica. A flexibilização do trabalho e do trabalhador está sob o comando de uma nova racionalidade do processo (re)produtivo do capital, vigorando de forma globalizada.

Essa acumulação flexível parece, ao mesmo tempo, implicar níveis relativamente altos de desemprego estrutural, ganhos modestos (quando existem) de salários reais, retrocesso do poder sindical e rápida destruição e reconstrução de habilidades. Criam-se novas especializações, alteram-se as relações entre as forças produtivas e articula-se diferentemente o trabalho intelectual e manual. O trabalhador, agora, não é apenas individual, mas coletivo. O que afeta um, afeta toda a categoria em escala global. Os trabalhadores migram, desterritorializam-se em busca de espaços e horizontes que incorporem suas condições de raça, sexo, língua, tradição, idade, religião, expectativa, sonho, ilusão. Um novo mapa do mundo se redefine pelo movimento mundial do capital, mas especialmente pelo movimento migratório dos trabalhadores.

Nesse contexto, a questão social surge como um novo desafio, manifesta-se em escala mundial, recriando diferentes aspectos, bem como engendrando novos. E estes afetam tanto os países subdesenvolvidos como criam subdesenvolvimento na periferia das cidades do chamado Primeiro Mundo.

\footnotetext{
${ }^{3}$ Em 28 de outubro de 2009 o Senado Federal aprovou por unanimidade a Proposta de Emenda à Constituição (PEC) 96A/03, que torna obrigatório o ensino para crianças e jovens de 4 a 17 anos. Já a partir de 2010, o poder público terá que oferecer o ensino médio público a todos os alunos que estiverem interessados em cursá-lo. O estudante continua podendo escolher se vai fazer ou não o ensino médio. Porém, a partir de 2016, o poder público e os pais poderão ser responsabilizados civil e criminalmente pelos que estiverem fora da escola como acontece atualmente dos 6 aos 14 anos.
} 
Alguns podem ser traduzidos pelo desemprego cíclico e estrutural; pelo acirramento das intolerâncias, preconceitos e discriminações ligadas à condição sexual, racial, política, de idade, de credo religioso, fazendo ressurgir movimentos racistas, xenófobos, separatistas, fundamentalistas, entre outros; pela migração que dissocia e desagrega famílias, ampliando a pauperização e provocando o crescente abandono da escola pela indiscutível necessidade do trabalho infantil e da exploração de menores; pelo crescimento de subclasses e de padrões indignos e subumanos de habitação, de fome, de saúde e de vida.

A perda do emprego é processo seletivo, que tem e não tem relação direta com o nível de escolarização - a chamada "educação" - dos trabalhadores. Ao mesmo tempo em que se adensam os trabalhos informais pela prestação de serviços, admitindo a pouca escolaridade como "natural", no âmbito dos trabalhos qualificados, a seleção se estabelece pelo predomínio das tecnologias e dos sistemas eletrônicos trabalhadores desencarnados que substituem, com vantagem, na linguagem do capital, os profissionais habilitados para funções precisas.

O direito ao trabalho e à educação do trabalhador como direitos sociais se complexificam. Tensionamse relações entre velhos e novos trabalhadores, uns apegados às conquistas históricas das quais usufruíram direitos, outros em disputa pelo direito ao trabalho, na ótica de ter alguma ocupação, em sociedades sem emprego. Os trabalhadores que se constituíram como tais pelo trabalho, e por esta via constituíram-se cidadãos, questionam-se sobre um futuro incerto, duvidoso e frequentemente admitem que a insegurança é culpa individual pela baixa escolaridade, pela pouca "educação". No entanto, como trabalhadores constituíram suas vidas, família, prole, educaram seus filhos, exerceram a cidadania, ensinando o mesmo valor que os constituiu, embora na prática, nem para si próprios, os valores sejam mantidos. Desempregados, alimentam a ilusão de novo emprego, buscando a chance renovada na escola ou nos cursos de formação profissional, para conseguir novos empregos, para mantê-los ou para ascender a níveis de maior prestígio.

O que caracteriza o mundo do trabalho nesse início de século é que este se tornou, realmente, global. Não se globaliza apenas o capitalismo, mas também o mundo do trabalho, impondo-lhe novas formas e novos significados. As mudanças afetam não apenas as forças produtivas em seus processos e dinâmicas, mas também a composição e a dinâmica da classe operária e a própria estrutura social, em âmbito local, nacional, regional e mundial. As questões sociais daí decorrentes não são retóricas, mas rompem com paradigmas e modos de pensar até então constituídos, para exigir novas compreensões e (re)significações de sentidos e manifestações.

Se, por um lado, a realidade do crescimento tem como aliados fortes representantes do poder econômico para garantir a investida do capital pela via do modelo neoliberal, ao mesmo tempo esse mesmo poder, representado por agências multilaterais, como o Fundo Monetário Internacional (FMI), já não pode mais deixar de defender nem prescindir da educação dos trabalhadores para constituir o avanço do projeto capitalista.

A recomendação das agências é a formação dos trabalhadores e não apenas de treinamento profissional, cuja prática mostrou ser insuficiente para dar conta da complexidade das exigências que as novas relações da produção fazem aos trabalhadores e aos sistemas produtivos. Se por um lado esta é uma realidade, por outro, a especialização constitui um fator a mais de exclusão do mercado de trabalho, que se vem reduzindo sensivelmente. As exigências não apenas impulsionam a formação dos trabalhadores como, ao mesmo tempo, tornam desnecessários postos de trabalho, pelas substituições que as tecnologias tendem a criar. Desse modo, para os trabalhadores não basta saber ler e escrever, mas há que ser leitor experiente, capaz de interpretar e (re)significar códigos e registros, situando seu processo de trabalho em um espectro mais amplo, que ultrapassa o âmbito do chão da fábrica. Já não é mais um trabalhador situado apenas em um tempo-espaço definido pelos limites da fábrica, mas um trabalhador do mundo globalizado, para o qual concorre, com seu trabalho, para a internacionalização da economia.

Contrariamente ao que se apregoava, "o mito da 'fábrica sem homens", o capital não se basta com a ciência e a tecnologia, sem a necessária intervenção da experiência humana do trabalho,

Muito ao contrário, ela nunca foi tão importante. Reduzido o apêndice da máquinaferramenta durante a revolução industrial, o homem, a partir de agora e inversamente aos lugares-comuns, deve exercer na automação funções muito mais abstratas, muito mais intelectuais. Não lhe compete, como anteriormente, alimentar a máquina, vigiá-la passivamente: compete-lhe controlá-la, prevenir defeitos e, sobretudo, otimizar o seu funcionamento. A distância entre o engenheiro e o operário que manipula os sistemas automatizados tende a desaparecer ou pelo menos deverá diminuir, se se quiser utilizar eficazmente tais sistemas. Assim, novas convergências surgem entre a concepção, a manutenção e uma produção material que cada vez menos implica trabalho manual e exige cada vez mais, em troca, a manipulação simbólica. (LOJKINE apud IANNI, 1996, p. 19). 
Pode-se assinalar como os trabalhadores, por exemplo, através dos conselhos em que se fazem representar, conquistam espaço para reivindicar o ensino fundamental e auferir os recursos capazes de fomentar e financiar ações de educação continuada para jovens e adultos. No espaço de participação que conseguem conquistar, inscrevem outros modos de negociar suas necessidades, promovendo instâncias mais democratizadas de decisão. Diferentes instituições passaram, então, a se ocupar com mais empenho da educação de adultos, representando uma prioridade significativa nas ações da área do trabalho.

Em muitos casos, os sistemas federal, estadual e municipal de ensino têm sido insuficientes para o desafio da garantia do direito à educação para os trabalhadores. Impossível confiar unicamente ao Estado a responsabilidade da questão educacional, sem envolver outros setores da sociedade civil, conjugados em uma ação visando a garantir o direito da cidadania. Sindicatos, associações de classe, federações, conselhos, centrais sindicais ocuparam este lugar, rompendo com a tradição de desacertos históricos que isolaram das propostas pedagógicas dirigidas aos trabalhadores a dimensão educativa da área do trabalho, com os diferentes e múltiplos conhecimentos que vêm sendo produzidos pelos próprios trabalhadores. Assim como romperam com a tradição autoritária de que só as elites são capazes de definir o que é melhor para os trabalhadores, não apenas buscando implementar os projetos que lhes são caros como classe, também buscam instaurar procedimentos democráticos, que incluem a negociação, o conflito de interesses, os jogos de poder.

O desafio de pensar direito e democracia na educação para segmentos tão desfavorecidos - que se superpõem a outros muitos direitos negados, em um mundo de exclusões renovadas - é, no atual contexto histórico brasileiro, assumido pelo Governo de Luiz Inácio Lula da Silva como prioridade.

No entanto, como ensina Santos (1999, p. 109), "os riscos que corremos em face da erosão do contrato social são demasiado sérios para que ante eles cruzemos os braços". Para superar esses riscos, o autor propõe reinventar a deliberação democrática a partir de uma "outra epistemologia ${ }^{4}$ para a qual o ponto de ignorância é o colonialismo e o ponto de saber é a solidariedade (conhecimento como emancipação)" (SANTOS, 1999, p. 110) e em que o trânsito da epistemologia moderna para esta se faça não simplesmente pela própria concepção de epistemologia, mas entre conhecimento e ação - ação rebelde, a que denomina ação-comclinamen $^{5}$. O autor assinala ainda que essa é uma ação turbulenta de um pensamento em turbulência. Por fim, entende que esta reinvenção da deliberação democrática implica a reconstrução de novos espaços-tempos que façam frente à compressão e à segmentação do espaço-tempo, e que possam incluir o local, o regional e o global, além de atender as exigências cosmopolitas, cujo sentido último é a construção de um novo contrato social.

Atribuindo aos sujeitos, no cotidiano, a possibilidade de reinventar a emancipação social, Santos (2002, passim) propõe a todos nós democratizar a democracia, sem o que a injustiça e a desigualdade não dão trégua às populações.

\section{EnTão, Para Onde Vamos?}

A legislação recomenda a necessidade de busca de condições, de alternativas, de currículos adequados a sujeitos jovens e adultos, levando em conta seus saberes, seus conhecimentos até então produzidos e suas experiências no mundo do trabalho etc., que não são poucos. Nessas experiências, esses sujeitos se formaram não na escola; por elas aprenderam conteúdos que determinam seus modos de estar no mundo, de aprender novas coisas, determinam seus interesses, seus desejos de saber mais, de certificar-se, de progredir, ou não, nos/pelos estudos (cf. Art. 37 e 38 LDBEN e Parecer CNE no. 11/2000).

A identidade de professores nem sempre se forma considerando os públicos com os quais vai/pode trabalhar. Cursos de formação, no mais das vezes, costumam enfatizar modelos organizativos, realidades e sujeitos de escolas chamadas "regulares", não formando professores para compreensões mais abrangentes do fenômeno educativo, de seus variados e potenciais sujeitos, das exclusões que o campo do direito ${ }^{6}$, do aprender e do não-aprender conformam na realidade educacional brasileira.

Especialmente quando se trata de professores da área de EJA, a situação tende a ser mais crítica pela forma como a sociedade desconhece e de certo modo mantém à margem a atividade docente com jovens e

\footnotetext{
${ }^{4}$ Boaventura de Souza Santos (1995, p. 25, apud 1999, p. 110) define que a epistemologia moderna faz sua trajetória de um ponto de ignorância, designado por ele de caos, para um ponto de saber, que designa de ordem, tomando o conhecimento como regulação.

5 "Clinamen é a capacidade de desvio atribuída por Epicuro aos átomos de Demócrito, um quantum inexplicável que perturba as relações de causa e efeito. O clinamen investe os átomos de criatividade e de movimento espontâneo. O conhecimento-como-emancipação é um conhecimento que se traduz em ações-com-clinamen". (SANTOS, 1999, p. 110).

${ }^{6}$ Entendido na perspectiva de direito humano fundamental, tal como expresso na Declaração dos Direitos Humanos de 1948 , que completou 60 anos.
} 
adultos, negando-a desde as políticas públicas, muitas vezes, até o uso das escolas, de seus equipamentos, aparelhos, dispositivos.

Nesse quadro, poder-se-ia pensar que a falta de formação só conferisse qualidade discutível ao professor, o que não é verdade. Sua capacidade para criar, para reinventar práticas e recriar o cotidiano faz com que, em relação dialógica com sujeitos jovens e adultos e com o mundo em que vivem, esse professor possa compreender suas exigências e, a partir delas, recriar seus quefazeres, ressignificando seu próprio conhecimento sobre ser professor.

A realidade vista por essa ótica exige ressaltar a prática diária desses sujeitos, pois é nela, realidade, que os sujeitos usam e recriam cotidianamente os conhecimentos produzidos a partir de sua inserção social e de classe.

O que precisam, então, saber jovens e adultos oriundos de projetos organizados para dar conta de aprendizagens descontínuas, frequentemente interrompidas, fragmentadas? Os conteúdos da escola ditos como saberes universais, imutáveis, diante de um mundo atônito, que a cada instante ensina e aprende tantas coisas, que produz a cada dia novos conhecimentos que vorazmente vão sendo assimilados ao cotidiano, alquimizados e ressignificados pelos praticantes da vida cotidiana? Que conhecimentos emergentes ajudam a projetar o futuro, que começa cotidianamente?

A base de toda a aprendizagem na contemporaneidade se sustenta mais nas condições necessárias para que se venha a aprender - crítica e criativamente - do que no conteúdo que se aprende, passível de ser encontrado em muitos lugares, desde que se possa e se saiba acessá-lo, assim como se saiba o que fazer com ele.

Qual será, então, o diferencial que faz pensar currículo para adolescentes e jovens de cursos regulares e para jovens e adultos na modalidade EJA? Que tênue linha separa uns e outros, ou faz, quando oferecido, uma significativa diferença positiva para o de EJA, seduzindo e envolvendo diversamente os sujeitos?

Nem todos os argumentos levariam a pensar o currículo como dado fundamental para essa positiva diferença. Mas o que tem sido observado, efetivamente, é que o currículo responde por grande parte dessa preferência, exatamente pela forma como vem sendo apropriado como instrumento de força pedagógica em projetos para jovens e adultos.

Ao se levar em conta saberes cotidianos, prévios, quase sempre ignorados na formulação curricular tradicional que encobre experiências sociais, históricas, culturais, de classe, de sociedade, de professores e alunos, trançam-se histórias e com elas saberes, conhecimentos, produzidos na vida cotidiana, formando redes que passam a emergir na realidade da escola, como emergem na realidade da vida. Não é, pois, qualquer currículo, mas aquele que se traduz como proposta que exige construção plena, feita com os grupos atendidos de sujeitos trabalhadores, nas diferentes realidades de cada escola em que se faz prática, por meio do projeto político-pedagógico.

Para isso, portanto, implica um movimento de (re)construção que não nega de modo algum as experiências, mas dialoga com elas, no sentido de investigá-las com um olhar de estranhamento. E é o professor quem deve estar lá, com as equipes e estudantes, pensando projetos de ensino de jovens e adultos, em processo permanente de autoformação.

Ao assumir esta concepção, necessariamente, assume-se uma visão não de parte da realidade, mas de sua totalidade, que comporta visões diferenciadas sobre ela, sem hierarquizações, mas confrontando-as, a partir de valores sociais e de classe que carregam, na tentativa de estabelecer novas sínteses. Com isso, o currículo que daí emerge não prioriza um conjunto de conteúdos, vinculado a uma única forma de pensar a sociedade, mas admite a contradição, os antagonismos e não escamoteia os diversos interesses em jogo quando se oferece o serviço educativo: os interesses dos que o propõem, o dos que o fazem e o dos que o "sofrem", porque quase sempre são excluídos dos seus conteúdos e de identidades sociais e de classe.

Para que esse currículo apareça, a marca que o faz acontecer é a da produção coletiva; é através da relação que as pessoas estabelecem umas com as outras, em sociedade, e por meio das quais aprendem; e, ainda, pelo forte traço educativo dessas relações. Essa marca coletiva valoriza não apenas saberes considerados de prestígio, mas (re)conhece todos os saberes de experiência feitos, como resultantes de processos culturais que a humanidade vem vivendo ao longo da sua história. Processos que não são únicos, mas vários, limitados e delimitados pelas maiores ou menores possibilidades em que inserções de classe, inserções de pessoas no modo de produção, pelo trabalho constituem o seu "estar no mundo". Mas processo sempre novo, sempre outro, porque admitindo a inventividade da criação humana como incontrolável, capaz de rupturas e de perplexidades, onde quer que se faça uma possibilidade de intervenção na realidade.

Esse currículo não tem de ser inventado. Ele existe, com maior ou menor grau de visibilidade nas escolas. Está lá, é praticado cotidianamente por professores e estudantes e com frequência não é assumido como currículo, mas entendido como extracurricular, ou co-curricular. 
Quais serão então, segundo esse modo de encarar currículo, os "conteúdos" de um currículo integrado à formação profissional, na escola de EJA? O que sabem jovens e adultos? O que sabem sobre o mundo do trabalho e do ser trabalhador? Que outros saberes portam e devem ser reconhecidos e confrontados com perspectiva de ampliação? Como fazê-lo? Onde estão esses saberes, como se entrelaçam aos "conteúdos" da escola e como, ao fazê-lo, tecem redes de conhecimento, que só efetivamente ganham sentido quando conseguem conectar-se, por fios a nós, a conhecimentos significativos produzidos pela experiência nas práticas sociais?

O sujeito humano, ser de relações que interage com elementos da natureza e com o mundo da cultura, com outros homens e mulheres e consigo mesmo, ao mesmo tempo interage em outro plano, aquele das relações simbólicas, quando cria representações que o orientam e o situam no mundo. Nestas relações simbólicas, apropria-se de costumes, valores e hábitos estabelecidos pelo grupo social do qual faz parte. Esta apropriação pode ser crítica ou acrítica, subordinando-o a falsas visões do mundo ou permitindo-lhe visão autônoma da realidade.

Isto significa que práticas sociais exercitadas pelos sujeitos em seus diferentes contextos, inclusive dentro do mesmo grupo, têm função educativa. Essas práticas são também exercitadas no contexto escolar, constituindo mais um vetor de desenvolvimento pessoal.

$\mathrm{Na}$ construção de uma escola para sujeitos jovens e adultos trabalhadores que os acolha, de modo que permaneçam aprendendo, cabe considerar, por um lado, o saber que resulta da prática social desse sujeito estudante e, por outro, os parâmetros que devem alicerçar esta construção, ou seja: quem é esse estudantetrabalhador, que saber traz e em que sujeito se quer (trans)formar?

\section{REFERÊNCIAS}

BOBBIO, Norberto. A era dos direitos. Trad. Carlos Nelson Coutinho. Rio de Janeiro: Campus, 1992.

BOSI, Alfredo. Dialética da colonização. 4.ed. São Paulo: Companhia das Letras, 1992.

BRASIL. Ministério da Educação. Programa de integração da educação profissional ao ensino médio na modalidade de educação de jovens e adultos - PROEJA. Documento base. Secretaria de Educação Profissional e Tecnológica. Brasília: SETEC/MEC, fev. 2006.

Conselho Nacional de Educação. Parecer CEB no. 11/2000. Diretrizes Curriculares para a Educação de Jovens e Adultos. Brasília: MEC, maio 2000.

. Constituição Brasileira. 5 de outubro 1988.

_. Lei de Diretrizes e Bases da Educação Nacional no. 9394/96. Brasília, 20 dez. 1996.

BUARQUE, Cristovam. Admirável mundo atual. Dicionário pessoal dos horrores e esperanças do mundo globalizado. São Paulo: Geração Editorial, 2001.

FREIRE, Paulo. Pedagogia da esperança. Um reencontro com a Pedagogia do Oprimido. Rio de Janeiro: Paz e Terra, 1992.

_. Cartas a Cristina. Rio de Janeiro: Paz e Terra, 1994.

IANNI, Otávio. O mundo do trabalho. In: FREITAS, Marcos Cezar de (org.). A reinvenção do futuro: trabalho, educação, política na globalização do capitalismo. São Paulo: Cortez; Bragança Paulista: USF-IFAN, 1996, p. 15-54.

MARTINS, José de Souza. Exclusão social e a nova desigualdade. 4. ed. São Paulo: Paulus, 2009.

NUNES, Clarice. Apresentação. In: TEIXEIRA, Anísio. Educação é um direito. 2.ed. Rio de Janeiro: Editora UFRJ, 1996. p. 7-18.

SANTOS, Boaventura de Sousa. Reinventar a democracia: entre o pré-contratualismo e o pós-contratualismo. In: OLIVEIRA, Francisco de, PAOLI, Maria Célia (orgs.). Os sentidos da democracia. Políticas do dissenso e hegemonia global. Petrópolis, Rio de Janeiro: Vozes; Brasília: NEDIC, 1999. p. 83-129.

SANTOS, Boaventura de Sousa (org.). Democratizar a democracia: os caminhos da democracia participativa. Rio de Janeiro: Civilização Brasileira, 2002.

MENESES, Maria Paula (orgs.). Epistemologias do Sul. São Paulo: Cortez, 2010.

SAWAIA, Bader (org.). As artimanhas da exclusão: análise psicossocial e ética da desigualdade social. 9. ed. Petrópolis, Rio de Janeiro: Vozes, 2009.

SEMERARO, Giovanni. Projetos de democracia popular nas organizações da sociedade civil brasileira: impasses e perspectivas político-pedagógicas. Projeto de pesquisa. Rio de Janeiro: UFF, jul. 1999. 16p. (mimeo). 